Please do not remove this page

RMIT

UNIVERSITY

\title{
Impact of gas injection on physicochemical properties of waste activated sludge: A linear relationship between the change of viscoelastic properties and the change of other physiochemical properties
}

Bobade, Veena; Evans, Geoffery; Baudez, Jean-Christophe; Eshtiaghi, Nicky

https://researchrepository.rmit.edu.au/esploro/outputs/9921863510401341/filesAndLinks?institution=61RMIT_INST\&index=null

Bobade, V., Evans, G., Baudez, J.-C., \& Eshtiaghi, N. (2018). Impact of gas injection on physicochemical properties of waste activated sludge: A linear relationship between the change of viscoelastic properties and the change of other physiochemical properties. Water Research, 144, 246-253.

https://doi.org/10.1016/j.watres.2018.07.041

Document Version: Accepted Manuscript

Published Version: https://doi.org/10.1016/j.watres.2018.07.041

Repository homepage: https://researchrepository.rmit.edu.au

(C) 2018 Elsevier Ltd. All rights reserved.

Downloaded On 2023/04/26 23:26:34 +1000 
Thank you for downloading this document from the RMIT Research Repository.

The RMIT Research Repository is an open access database showcasing the research outputs of RMIT University researchers.

RMIT Research Repository: http://researchbank.rmit.edu.au/

\section{Citation:}

Bobade, V, Evans, G, Baudez, J and Eshtiaghi, N 2018, 'Impact of gas injection on physicochemical properties of waste activated sludge: A linear relationship between the change of viscoelastic properties and the change of other physiochemical properties', Water Research, vol. 144, pp. 246-253.

See this record in the RMIT Research Repository at:

https://researchbank.rmit.edu.au/view/rmit:48748

Version: Accepted Manuscript

Copyright Statement:

(C)2018 Elsevier Ltd. All rights reserved.

This work is licensed under a Creative Commons Attribution 4.0 International License.

Link to Published Version:

https://dx.doi.org/10.1016/j.watres.2018.07.041 


\section{Accepted Manuscript}

Impact of gas injection on physicochemical properties of waste activated sludge: A linear relationship between the change of viscoelastic properties and the change of other physiochemical properties

Veena Bobade, Geoffery Evans, Jean Christophe Baudez, Nicky Eshtiaghi

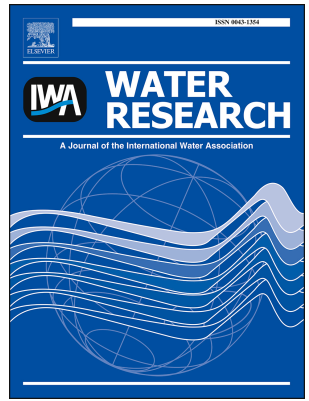

PII:

S0043-1354(18)30584-0

DOI: 10.1016/j.watres.2018.07.041

Reference: WR 13940

To appear in: Water Research

Received Date: 29 March 2018

Revised Date: 16 June 2018

Accepted Date: 16 July 2018

Please cite this article as: Bobade, V., Evans, G., Baudez, J.C., Eshtiaghi, N., Impact of gas injection on physicochemical properties of waste activated sludge: A linear relationship between the change of viscoelastic properties and the change of other physiochemical properties, Water Research (2018), doi: 10.1016/j.watres.2018.07.041.

This is a PDF file of an unedited manuscript that has been accepted for publication. As a service to our customers we are providing this early version of the manuscript. The manuscript will undergo copyediting, typesetting, and review of the resulting proof before it is published in its final form. Please note that during the production process errors may be discovered which could affect the content, and all legal disclaimers that apply to the journal pertain. 


\section{Impact of gas injection on physicochemical}

\section{2 properties of waste activated sludge: A linear} realationship between the change of

4 viscoelastic properties and the change of other physiochemical properties.

6

7 Veena. Bobade ${ }^{1}$, Geoffery Evans ${ }^{2}$, Jean Christophe Baudez ${ }^{3}$, Nicky. Eshtiaghi ${ }^{1}{ }^{*}$

$9{ }^{1}$ RMIT University, School of Civil, Environmental and 10 chemical Engineering, 124 La Trobe St, Melbourne, Vic 113000 , Australia.

${ }^{2}$ School of Chemical Engineering, The University of

13 Newcastle, Australia.

$14{ }^{3}$ LIST, Environmental Research and Innovation Department

15 (ERIN), 41, rue du Brill, L-4422 Belvaux, Luxembourg.

16 * Corresponding Author: Nicky.eshtiaghi@rmit.edu.au

18 Abstract

19 Aeration process in the waste activated sludge treatment accounts for $75 \%$ of total energy consumption of the treatment plant. The main purpose of the aeration process is to enhance the 
biodegradation of the liquid waste. Gas bubbles, rising through the

23 liquid, improves mixing, reduces inhomogeneities in the treatment tank and enhances biological reactions. Thus aeration intensity and several physicochemical properties of feed such as viscosity, total suspended solids, and surface charge play a significant role in the

27 biological reaction.

This paper examines the impact of the gas injection rate on some physicochemical properties of waste activated sludge namely rheological properties, suspended solids, soluble COD (sCOD), surface tension, and zeta potential. The impact of four different gas flow rates on four different concentrations of waste activated sludge properties was analysed.

The results showed that in linear viscoelastic regime the viscous and elastic modulus decreases linearly with an increase in gas flow rate. The amount of stress imposed by gas injection also showed a direct relationship with gas velocity. Gas injection also showed a substantial impact on soluble COD, suspended solids, and zeta potential. Additionally, a linear relationship was observed between the percentage change in the above mentioned physical properties and stress imposed by gas injection. These results confirm that gas injection produces additional shear impacting sludge

43 physicochemical properties and therefore changes its rheological

44 behaviour. The extra stress induced by gas injection can be

45 predicted using a simple model based on sludge concentration and 46 gas velocity 
47 Keywords: waste activated sludge, viscoelastic Properties,

48 suspended solids, soluble COD, zeta potential

\section{Introduction}

The waste activated sludge process is the most versatile and commonly used biological treatment (Seyssiecq et al. 2008). The efficiency of the waste activated sludge process depends upon an aeration operation. Aeration provides oxygen to the microorganisms to breakdown the complex organic compounds into carbon dioxide and water and reduces the volume of sludge produced (Bailey et al. 2002). However, the oxygen transfer rate in the aeration tank decreases with an increase in the total solid concentration of sludge and strongly influences the efficiency of the process (Rosenberger et al. 2002). This is because with increasing solid concentration of sludge results in an increased viscosity of sludge that causes variations in system hydrodynamics as and impacts on bubble buoyancy, bubble shape and turbulence (Bajón Fernández et al. 2015).

Waste activated sludge is composed of water, microorganisms, and macromolecules grouped in bioflocs (Laspidou and Rittmann 2002). Hence it's structure depends on many factors and can remarkably change when exposed to shear stress. Therefore, sludge is known to exhibit shear thinning behaviour (Eshtiaghi et al. 2013, Baudez and Coussot 2001, Baudez 2008). Thus, rheology plays a crucial role in optimising and designing the aeration system. Since the sludge characteristics and rheology affect each other, the impact of 
aeration on rheology and sludge physical properties should be tank.

Increase in aeration intensity results in a severe breakup of sludge

76 flocs, and promotes the release of colloids and solutes from the

77 microbial flocs to the bulk solution (Meng et al. 2008).

Consequently, it influences the sludge physical properties like total suspended solids (TSS), sludge volume index (SVI), etc. and impacts on sludge settleability, filterability, and compressibility (Pollice et al. 2007). The impact of shear stress generated by aeration intensity increased the soluble contents of sludge (SMP, EPS) (Menniti et al. 2010, Menniti et al. 2009). Moreover, the induced shear stress by microbubbles broke down the sludge that reduced the floc size and released the organic content such as EPS and it also changed the viscosity and surface tension of sludge (Liu et al. 2012). Almost all

87 the studies that have conducted to date have only focused on membrane bioreactor to study the impact of aeration intensity on sludge physical properties and for the solid concentration less than $2 \%$. properties and consequently changes its rheological properties, currently there isn't any study that showed the relationship

94 between sludge rheology (especially in a linear viscoelastic region

95 that can be measured online) and physiochemical properties of sludge. 
As both the physical and rheological properties simultaneously change in the aeration process and impact on the efficiency of the waste activated sludge process, monitoring shear and its effect on complex physicochemical properties through online tools (e.g. rheometers) with any minor change provides useful information to adjust operating conditions accordingly. However, there is lack of detailed analysis on the change in sludge rheology with anaeration rate and its impact on the sludge physicochemical properties. This study wants to elucidate and correlate the stress generated by aeration intensity with sludge physicochemical properties. Therefore this research primarily aims at investigating the impact of gas injection on viscoelastic properties, zeta potential, soluble COD and surface tension to get the detailed insight of the shear induced by the gas intensity and its effect on sludge physicochemical properties. The second objective is to develop relationships between change in rheological properties and physical properties at the different gas flow rates.

\section{Materials and Methods}

\subsection{Sample preparation}

Waste activated sludge with $3 w t \%$ (TS 30g/l; TSS 26.833g/l; sCOD $3720 \mathrm{mg} / \mathrm{l}$; zeta potential $-16.4 \mathrm{mv}$; surface tension $46.04 \mathrm{mN} / \mathrm{m}$ ) was collected from a wastewater treatment plant (Mt.Martha Treatment Plant) in southern region of Victoria, Australia. Sewage sludge of 600,000 customers after girt removal and primary tank settleing is areated in ambient temperature. The sludge samples 
122 were collected after the dissolved air flotation tank before the

123 polymer dosing. The sludge was thickened to higher concentration

124 (6\%) using a centrifuge at $7^{\circ} \mathrm{C}$ and $8000 \mathrm{rpm}$ (i.e., at $12,200 \mathrm{~g}$

125 maximum relative centrifugal force) for 30 minutes. The

126 homogeneous samples of $3.0 \%, 4.0 \%, 5.0 \%$ \& $5.5 \%$ total solids

127 concentration (TS) were prepared by diluting the $6 \%$ concentrated

128 sludge with the original sample.

\subsection{Apparatus}

Rheological measurements were performed using commercially available hybrid stress controlled (HR3) rheometer from TA Instruments using a grooved bob geometry with an outer diameter of $14.9 \mathrm{~mm}$, and $42 \mathrm{~mm}$ length. A custom designed plexiglass cup (inner diameter: $100 \mathrm{~mm}$, length: $100 \mathrm{~mm}$ ) with a stainless steel porous disk (outer diameter: $100 \mathrm{~mm}$, thickness: $1.6 \mathrm{~mm}$, porosity: $40 \%$, from SINTEC Australia) at the bottom was used for sparging gas while it connected to rheometer (Bobade et al. 2017). The gas flow

138 rate was varied from $0.001 \mathrm{~m}^{3} / \mathrm{min}$ to $0.007 \mathrm{~m}^{3} / \mathrm{min}$ using a gas mass

139 flow meter from AALBORG at a pressure of 10 Psi.

\subsection{Rheometric technique}

141 To monitor the evolution of structural changes in sludge due to gas

142 injection, dynamic time sweep measurement was carried out. The

143 experimental procedure for the time sweep measurement was

144 carried out in the following pattern: 
- Step 1: Pre shear the sludge at high shear rate $\left(350 \mathrm{~s}^{-1}\right)$ for 900 s to ensure that identical condition is achieved before each measurement.

- Step 2: The sludge was allowed to rest for a short time (120s) to start the test in the same condition (Baudez 2008, Markis et al. 2014).

- Step 3: The dynamic time sweep test at $0.09 \%$ strain and $1 \mathrm{HZ}$ frequency in a linear viscoelastic range was carried out for 1500s.

- Step 1: Preshearing of sludge at $350 s^{-1}$ for $900 s$; resting for 120s;

- Step 2: Dynamic time sweep measurement at different strains and $1 \mathrm{HZ}$ frequency without areation;

- Step 3: Compare the viscoelastic response $\left(G^{\prime}, G^{\prime \prime}\right)$ of non aerated sludge with the aerated sludge at $0.09 \%$ strain, the difference between the two strains showed the extra strain imposed. The detailed sketch diagram of the rheological 

(2017).

\subsection{Physicochemical properties}

173 Soluble COD (sCOD) and Zeta potential were examined to study the

174 sludge solubilisation after gas injection. The sample collected for

175 measuring the SCOD and Zeta potential was centrifuged at 10,000

176 rpm (i.e.,20913g at maximum relative centrifugal force) for $20 \mathrm{~min}$

177 for separating the liquor from solid. The small volume of obtained

178 liquor was used directly for zeta potential measurementand rest of

179 the liquor was filtered through a $0.45 \mu \mathrm{m}$ filter membrane. The

180 collected filtrate was used to determine SCOD following standard

181 American methods (Eaton et al. 2005). All measurements were

182 carried out in duplicate. To avoid any alteration of sludge properties

the samples and liquor are stored in a fridge at $4^{\circ} \mathrm{C}$.

184 The zeta potential measurement was performed using zetasizer

185 Nano Range from Malvern Instruments, using disposable folded

186 capillary cells (DTS 1070). The measurement was carried out at $20^{\circ} \mathrm{C}$,

187 keeping the time lag of 10 s between each set of readings. Each

188 measurement was repeated for three times. The standard maximum

189 deviation is $5 \%$.

190 A surface tension of fluid changes with any change of formulation at 191 the molecular level and helps to know the dispersibility and 192 adhesion of the fluid (Davies and Rideal 1963). The measurement of 193 surface tension was performed by using Force Tensionmeter (K100) 194 from Kruss (Germany) using plate method. Sludge being a non195 Newtonian viscous fluid, the measurement was carried out using 
microscope glass slide for $1200 \mathrm{~s}$ at an immersion depth of $2 \mathrm{~mm}$. For precise measurement of surface tension, the glass slide was activated using oxygen flame before each measurement. Different immersion depth and time of run was examined to find an optimum point to obtain reproducible data.

201

3.1 Influence of Aeration Intensity on Viscoelastic Properties

The oscillatory time sweep carried out in the linear viscoelastic region at low applied sinusoidal strain helps to understand whether any change in structure is occurring during gas injection. Both the storage modulus $\left(G^{\prime}\right)$ \& loss modulus $\left(G^{\prime \prime}\right)$ are impacted by gas injection as they are decreasing when the gas flow rate is increasing. At different solid concentrations, viscoelastic modulus [storage modulus $\left(G^{\prime}\right)$ \& loss modulus $\left.\left(G^{\prime \prime}\right)\right]$ vs. time was plotted. One sample graph is presented in Fig. 1 (Bobade and Eshtiaghi 2018 Figshare). This figure indicates the impact of different gas flow rates on the modulus of sludge with $3 w t \%$ total solids. A similar effect of gas

215 intensity on sludge modulus was observed for all the four

216 concentrations at four different gas flow rates during oscillatory

217 time sweep(Bobade and Eshtiaghi 2018 Figshare) (see the supplementary material, fig. S1-S3). The percentage change of average sludge modulus due to aeration intensity, i.e., $\left(\frac{\left(\text { Avg of } G^{\prime} \text { at without gas }- \text { Avg of } G^{\prime} \text { at given gas flowrate }\right)}{\left(\text { Avg of } G^{\prime} \text { at without gas }\right)}\right) * 100$ 
obtained during the measurement for all the four concentrations by

222 four different gas flow rates is shown in Table 1. This change in

223 sludge modulus with gas intensity indicates that sludge structure is

224 impacted by gas injection because the gas injection is applying

225 additional shear (Bobade et al. 2017). Such modification of sludge

226 structure may be attributed to the release of soluble components

227 due to floc dissolution (Meng et al. 2008). Similarly, it was reported

228 that the increase in aeration intensity enhances the release of

229 soluble components, which further decreases the oxygen transfer

230 efficiency (Meng et al. 2007, Menniti et al. 2010) by impacting on

231 food to microorganism ratio. As more soluble material means more

232 food and less oxygen available for microorganism to consume.

\subsubsection{Amount of Shear strain /stress imposed by} gas injection

The extra strain imposed by gas injection showed that the imposed strain increases with increase in gas flow rate but decreases with increase in concentration as shown in Table 2. Furthermore, the equivalent shear stress imposed is calculated by using Equation 1 (Mezger 2011).

$$
\tau=G^{*} \gamma
$$

, where, sludge over 20min measurement time, $(\mathrm{Pa})$ 
246 The amount of stress imposed by different gas velocities for

247 different concentrations was plotted in Fig. 2 (Bobade and Eshtiaghi

2482018 Figshare). The linear increase of stress with gas velocity was

249 observed for the entire concentration range. This result indicates

250 that for a given concentration the stress imposed by gas injection

251 increases linearly. In contrast, for the same gas velocity, the amount

252 of imposed stress decreases linearly with an increase in sludge

253 concentration, i.e., at high solid concentrations of sludge the shear

254 caused by the gas injection decreases. The reduction in imposed

255 stress by gas injection with an increase in solid concentration is

256 because sludge becomes more viscous and possesses a strong force

257 of attraction between particles as the concentration increases

258 (Baroutian et al. 2013). Also, to better understand the stress

259 imposed by gas flow rate at the different concentration of sludge,

260 the obtained data (refer Table 2) is analysed using linear multiple

261 regression method and an equation is derived (Eq. 2). In which its

262 fitting parameters are linked to measurable parameters in the

263 sludge to increase the applicability of this equation 3 to other

264 systems. The equation was also applicable with $\pm 10 \%$ error to

265 another waste activated sludge sample collected from Eastern

266 Treatment plant in Eastern region of Victoria. The equation 3 is

267 significant at $95 \%$ of confidence level with a $\mathrm{P}$ value much less than

2680.05 and with an $R^{2}$ value of 0.88 . The estimated error is $\pm 7 \%$

269 within the range of concentration studied with $0.5 \%$ for lowest

270 concentration and $7 \%$ for the highest concentration. 
273 , where,

$275 \mathrm{Ug}=$ Gas velocity, $(\mathrm{m} / \mathrm{s})$

276 TS $=$ Concentration of total solids, $(\mathrm{g} / \mathrm{g})$

$$
\sigma_{\text {imposed }}=\left(\frac{\left(0.0135 * T S^{2}\right)}{T_{S S}^{2 *} D_{p}}\right) * \mu_{(\text {water })} * U_{g^{-}}\left(\frac{10 * T S^{2}}{T_{S S}}\right)
$$

278 Where,

$279 \mathrm{~T}_{\mathrm{ss}}=$ Total suspended solids of unaerated sludge $(\mathrm{g} / \mathrm{g})$

$\mathrm{TS}=$ Total solids concentration $(\mathrm{g} / \mathrm{g})$

281

$D_{p}=$ Diameter of the Pore of the membrane ( in this study is 0.00002

282

m)

283

$\mu_{\left(\text {Water } @ 20^{\circ} \mathrm{C}\right)}=$ Viscosity of water $=1 \mathrm{Ns} / \mathrm{m}^{2}$

\subsection{Influence of Aeration Intensity on Total Suspended}

\section{Solids ( $\left.\mathbf{T}_{\mathrm{ss}}\right)$}

Suspended solids mostly consist of colloidal and particulate particles

287 (Meng et al. 2017, Trussell et al. 2007). Fig. 3 illustrates the

288 decreasing trend of suspended solids with increasing gas velocity. It means that as the gas velocity increases, the amount of solids that can pass through filter increases, i.e., gas intensity breaks the suspended particles into smaller fragments and a large number of smaller particles settles causing fouling issue. However, it is also 
293

294

295

296

297

298

299

300

301

302

303

304

305

306

$\% \Delta T_{s s}=a^{*} \sigma_{\text {imposed }}$

, where,

clear from Fig. 3, that as the concentration increases, reduction in suspended solids decreases, i.e., at higher concentration and for the same gas velocity, the stress imposed by gas velocity is not sufficient to break down the suspended particles into submicron particles. Zhang et al. (2004) also found that suspended solids gradually decrease with increasing aeration intensity. This reduction in suspended solids due to aeration intensity is the consequence of the floc breakage and releasing EPS present inside the floc structure (Chang et al. 2002), which consequently decreases an oxygen transfer efficiency due to increase in food to microorganism ratio (Houghton and Quarmby 1999, Meng et al. 2006, Wilén et al. 2003).

Interestingly, there is a linear relationship between stress imposed by gas injection and the change in suspended solids at given condition and for given concentration (Eq. 4). This linear relation has $95 \%$ of confidence level and $p$-value much less than 0.05 with \pm $5 \%$ error which is the highest related to sludge with the highest concentration. Utilising an online rheometer and obtaining viscoelastic properties of sludge and the stress imposed by the gas injection can give us a better understanding of the influence of aeration intensity on suspended solids.

$\sigma_{\text {imposed }}=\quad$ Stress imposed by the gas velocity at any solids concentration studied (3-5.5\%), (N/m²) 
$317 \% \Delta \mathrm{T}_{\mathrm{ss}}=\quad$ Percentage change in suspended solids compared to

318 non areated sludge, (\%)

$319 \mathrm{a}=\quad$ Fitting parameter $=2.01,\left(\mathrm{~m}^{2} / \mathrm{N}\right)$

320 This decrease in suspended solids is due to change in floc structure

321 caused by the aeration was also confirmed by measuring the

322 viscoelastic properties of aerated sludge immediately after sparging

323 and after resting the sludge for 40 minute as shown in Fig.4. It is

324 obvious that after 20 mins of gas injection, $G^{\prime}$ reduced by (13\%) also

325 after stopping gas injection and giving 40 mins of rest time, the

326 sludge structure was not returned to original structure as the $G^{\prime}$ is

$3278 \%$ less than the $\mathrm{G}^{\prime}$ of the non aerated system.

\subsection{Influence of Aeration Intensity on Soluble COD} (sCOD)

The soluble COD is one of the critical parameters for estimation and optimisation of the performance of the biological treatment process (Hayet et al. 2016). The sCOD content is also used to determine the amount of oxygen required for the biodegradation in the aeration tank(Henze and Henze 1997). Thus the impact of aeration intensity on the soluble COD (sCOD) of the sludge sample was measured at different concentrations and at different gas injection rates as presented in Table 3.

A linear increase in SCOD was observed with an increase in gas velocity over the entire concentration range. Additionally, the results indicated that at $0.01274 \mathrm{~m} / \mathrm{s}$ of gas velocity, more organic matter is released from solid phase to liquid phase. A similar 
342 increase in soluble COD with an increase in aeration intensity was

343 also observed by Meng et al. (2008) and very well explained that the

344 shear-induced by gas leads to floc breakage and increases the

345 soluble contents in the sludge. Azami et al. (2012), Ladewig and Al-

346 Shaeli (2016), Meng et al. (2006) have also highlighted that role of

347 soluble microbial products (SMP), which is characterized as soluble

348 chemical oxygen demand (sCOD) on the kinetic activity, flocculating

349 and settling properties of sludge.

350 The increase in soluble COD, therefore confirms that the shear

351 induced by gas injection impacts on floc structure releases EPS and

352 increases the soluble contents causing a decrease in viscoelastic

353 properties. Hence, it is necessary to consider the impact of shear

354 force induced by the gas injection on the sludge and increase in

355 sCOD together for efficient operation of the treatment plant.

356 Additionally using multiple regression analysis, the percentage

357 change in SCOD has a linear relationship with stress imposed for all

358 concentration studied (Eq. 5). This equation has a confidence level

359 of $95 \%$ with $R$ square value of 0.96 and a $P$ value much smaller than

3600.05 with an error range of $\pm 15 \%$ for lower concentration and

361 inceases upto $\pm 30 \%$ at higher concentrations.

$$
\% \triangle S C O D=b^{*} \sigma_{\text {imposed }}
$$

, where, 


\section{ACCEPTED MANUSCRIPT}

$366\left(\mathrm{~N} / \mathrm{m}^{2}\right)$

368 compared to non-aerated sludge, (\%)

\subsection{Influence of Aeration Intensity on Zeta potential}

371 The zeta potential, which measures the surface charge / electrostatic interactions between the particles, represents the potential drop between the diffuse double layers of the surface. This analysis helps to get detailed insight into the cause of dispersion, aggregation, flocculation \& sedimentation (Hunter 1981, Vold 1982,

Yuan et al. 2011).

The zeta potential of waste activated sludge at given total solids concentration, linearly decreased (become more negative) with increasing gas velocity (Fig. 5). The reduction in zeta potential i.e. the zeta potential value becoming more negative indicates that the sludge is becoming more stable because the repulsive force is more than the attractive force (Lu and Gao 2010). Thus the resistance to aggregation is increasing (Vold 1982). The zeta potential also increased with increasing total solid concentration and became less negative. The less negative zeta potential values confer that the attractive force is exceeding the repulsive force and decreasing the

387 stability (resistance to aggregation/agglomeration) of the sample and increasing the coagulation \& flocculation behaviour. Similarly, 
zeta potential value becomes less negative with an increase in solid concentration at a constant aeration rate of $0.2 \mathrm{~m}^{3} / \mathrm{h}$ as reported by

Meng et al. (2006). Interestingly, an increase in zeta potential with an increase in total suspended solids is also reported by (Su et al. 2014). Additionally, Sutherland (2001) also showed that EPS plays a crucial role in defining the stability of the system as each structural cell of polysaccharide forms intra-or inter-molecular associations that leads to gelation. However, this gelation varies greatly depending on the type of inter or intramolecular hydrogen bonding which contributes to floc formation, stability, etc.

Therefore, the more negative surface charge of sludge with an increase in gas velocity indicates that gas injection modifies the sludge characteristics because of increased solubilisation of loosely bound EPS (LB-EPS)(Zhang et al. 2013). A linear correlation between stress imposed by gas injection and the percentage change in zeta potential as presented in Eq. 6 was found through multiple regression method with a $P$ value less than 0.05 and $R$ square value of 0.92 . The percentage error is $\pm 5 \%$. Zeta potential crucially reflects the stability of the system and affects the overall performance of the process. Moreover, the knowledge of zeta potential and hydrophobicity is important to understand the electrostatic interaction between SMPs with membrane surface and

411 flocculation potential in activated sludge process (Azami et al. 2012,

412 Chen et al. 2012). Thus the knowledge of a change in zeta potential 413 with stress imposed by gas flow rate will help to optimise the operation of waste activated sludge process. 
415

$$
\% \Delta \zeta=c^{*} \sigma_{\text {imposed }}
$$

416

417

$\% \Delta \zeta$

Percentage change in Zeta potential

418

compared to the non areated system (\%)

419

$\sigma_{\text {imposed }}=\quad$ Stress imposed by gas injection at a

420 given concentration $\left(\mathrm{N} / \mathrm{m}^{2}\right)$

421

$$
\text { c } \quad=\quad \text { Fitting parameter }=2.12,\left(\mathrm{~m}^{2} / \mathrm{N}\right)
$$


423 The change in interfacial surface tension of sludge with gas velocity

424 is shown in Table 4. The interfacial surface tension is observed to

425 increase linearly with increase in gas velocity for all the

426 concentrations studied $\left(R^{2}=0.9\right)$. (Note: All the surface tension

427 reported here are at the 1200 s of the time interval). As the

428 concentration increases the time required by the surface tension

429 curve to reach steady state increases, i.e., the surface tension curve

430 has not reached the stable value at the 1200 s and hence shows a

431 large difference in surface tension value even at no gas.) As the

432 concentration increases, the intermolecular force in the sludge

433 increases and results in bubble coalescence, thereby impacting

434 more on surface tension. Hence the percentage change of surface

435 tension is more at high concentration of sludge and low gas flow

436 rate as shown in Figure 6.

437 Interestingly it was also observed that gas velocity has a linear

438 correlation with the percentage change in surface tension at a given

439 concentration.

440 The surface tension is closely related to carbohydrates, and protein

441 content of EPS as those are amphiphobic molecules and could

442 change the surface tension of the fluid (Sheng et al. 2010).

443 Moreover, a direct relationship was reported by by Schonhorn

444 (1965) between surface tension and cohesive energy of the

445 molecule. And the cohesion of sludge increases with increasing the

446 polysaccharide content of EPS (Ahimou et al. 2007). In addition, 
447 there is a direct relation between interfacial surface tension and

448 bio flocculation i.e. when the fine dispersed particles are clumped

449 together and a big agglomerated floc is formed, and settling of

450 organic matter takes place more which then results in reducing the

451 interfacial surface tension (Liss and Droppo 2005). Thus, gas

452 injection induces shear and increases the sludge stability which

453 means resistance to aggregation increases (more negative Zeta

454 potential) and results in measuring higher value for surface tension.

455 This understanding of surface tension and gas flow rate at a given

456 concentration will help to understand orientation time and growth

457 time of bubble (Kulkarni and Joshi 2005). During the bubble

458 formation and detachment process, two types of surface tension

459 forces act on a bubble, dynamic and static. At the initial growth

460 phase, the surface tension is dynamic as its contact angle with the

461 orifice changes continuously and in the later part, it reaches to a

462 constant contact angle approaching to static. Thus although the

463 surface tension forces are small, they vary significantly with gas

464 flowrates and impacts on buble formation. In addition, considering

465 the surface tension change with the strain imposed by gas injection

466 together is important to understand the bubble coalescence

467 phenomena and gas distribution behaviour. This will further help to

468 optimise the hydrodynamics of the system since bubble

469 characteristics depend on the viscous property and the surface

470 tension of the fluid (Sikorski et al. 2009). 


\section{Conclusion}

472 The impact of gas injection on the physiochemical and rheological

473 properties of sludge is elucidated. The viscoelastic modulus of

474 sludge decreased with an increase in gas flow rate resulting in

475 weakening of sludge structure. The gas flow rate induced shear, and

476 the intensity of shear-induced linearly increased with increasing gas

477 velocity. However, for the same gas flow rate, the shearing intensity

478 decreased with increasing total solids concentration of sludge.

479 A linear relationship was observed between the change in 480 suspended solids, soluble COD, and zeta potential with an increase

481 in stress induced by gas injection. This change in physiochemical

482 properties is because of break down of floc structure.. The decrease

483 in zeta potential values also proved that gas injection modifies the

484 sludge surface by changing the stability of the system which in turn

485 increases the surface tension linearly with increase in gas velocity. .

486 Thus observing the change in rheological properties due to gas

487 injection intensity is also useful to understand the changes in

488 physicochemical properties of sludge that are responsible for

489 efficient and optimised operation of waste activated sludge

490 treatment. 
496

497

498

499

500

501

502

503

504

505

506

507

508

509

510

511

512

513

514

515

516

517

518

519

520

521

522

523

524

525

526

527

528

529

530

531

532

533

534

535

536

537

The Authors acknowledge South East Water support for providing

sludge, to carry out the research, and RMIT University to provide

Australian Government Research Training Program Scholarship for

V. Bobade.

\section{References}

Ahimou, F., Semmens, M.J., Haugstad, G. and Novak, P.J. (2007) Effect of protein, polysaccharide, and oxygen concentration profiles on biofilm cohesiveness. Applied and environmental microbiology 73(9), 2905-2910.

Azami, H., Sarrafzadeh, M.H. and Mehrnia, M.R. (2012) Soluble microbial products (SMPs) release in activated sludge systems: a review. Iranian Journal of Environmental Health Science \& Engineering 9(1), 30-30.

Baroutian, S., Eshtiaghi, N. and Gapes, D.J. (2013) Rheology of a primary and secondary sewage sludge mixture: Dependency on temperature and solid concentration. Bioresource Technology 140, 227-233.

Baudez, J.C. (2008) Physical aging and thixotropy in sludge rheology. Applied Rheology 18(1), 13495-13491-13495-13498.

Bobade, V., Baudez, J.C., Evans, G. and Eshtiaghi, N. (2017) Impact of gas injection on the apparent viscosity and viscoelastic property of waste activated sewage sludge. Water Research 114, 296-307.

Bobade, V. and Eshtiaghi, N. (2018 Figshare) Dynamic time sweep measurement of sludge for four different concentrations (3\%, $4 \%$, $5 \%$ \& $5.5 \%$ ) at four different gas flow rates (1 Lpm to 7 LPM), https://figshare.com/s/87454a1b2f8b5ccaf03c. Chang, I.-S., Le Clech, P., Jefferson, B. and Judd, S. (2002) Membrane fouling in membrane bioreactors for wastewater treatment.(Abstract). Journal of Environmental Engineering 128(11), 1018.

Chen, L., Tian, Y., Cao, C.-q., Zhang, J. and Li, Z.-n. (2012) Interaction energy evaluation of soluble microbial products (SMP) on different membrane surfaces: Role of the reconstructed membrane topology. Water Research 46(8), 2693-2704.

Davies, J.T. and Rideal, E.K. (1963) Interfacial phenomena, Academic Press, New York.

Eaton, A.D., American Public Health, A., American Water Works, A. and Water Environment, F. (2005) Standard methods for the examination of water and wastewater, APHA-AWWA-WEF, Washington, D.C.

Hayet, C., Saida, B.-A., Youssef, T. and Hédi, S. (2016) Study of biodegradability for municipal and industrial Tunisian wastewater by 
538 respirometric technique and batch reactor test. Sustainable

539 Environment Research 26(2), 55-62.

540 Henze, M.A. and Henze, M. (1997) Wastewater treatment :

541 biological and chemical processes, Springer, Berlin, Heidelberg,

542 [Germany].

543 Houghton, J.I. and Quarmby, J. (1999) Biopolymers in wastewater

544 treatment. Current Opinion in Biotechnology 10(3), 259-262.

545 Hunter, R.J. (1981) Zeta Potential in Colloid Science, pp. 1-10,

546 Academic Press.

547 Kulkarni, A.A. and Joshi, J.B. (2005) Bubble Formation and Bubble

548 Rise Velocity in Gas-Liquid systems -A Review. Industrial \&

549 Engineering Chemistry Research 44, 5873 - 5931.

550 Ladewig, B. and Al-Shaeli, M.N.Z. (2016) Fundamentals of Membrane Bioreactors: Materials, Systems and Membrane Fouling, Springer.

Liss, S.N. and Droppo, I.G. (2005) Flocculation in natural and engineered environmental systems, CRC Press, Boca Raton. Liu, C., Tanaka, H., Ma, J., Zhang, L., Zhang, J., Huang, X. and Matsuzawa, Y. (2012) Effect of microbubble and its generation process on mixed liquor properties of activated sludge using Shirasu porous glass (SPG) membrane system. Water Research 46(18), 60516058.

560 Lu, G.W. and Gao, P. (2010) Handbook of Non-Invasive Drug Delivery 561 Systems, pp. 59-94, William Andrew Publishing, Boston.

562 Markis, F., Baudez, J.-C., Parthasarathy, R., Slatter, P. and Eshtiaghi, 563 N. (2014) Rheological characterisation of primary and secondary 564 sludge: Impact of solids concentration. Chemical Engineering Journal 565 253, 526-537.

566 Meng, F., Shi, B., Yang, F. and Zhang, H. (2007) New insights into 567 membrane fouling in submerged membrane bioreactor based on 568 rheology and hydrodynamics concepts. Journal of Membrane 569 Science 302(1-2), 87-94.

570 Meng, F., Yang, F., Shi, B. and Zhang, H. (2008) A comprehensive 571 study on membrane fouling in submerged membrane bioreactors 572 operated under different aeration intensities. Separation and 573 Purification Technology 59(1), 91-100.

574 Meng, F., Zhang, H., Yang, F., Zhang, S., Li, Y. and Zhang, X. (2006) 575 Identification of activated sludge properties affecting membrane 576 fouling in submerged membrane bioreactors. Separation and 577 Purification Technology 51(1), 95-103.

578 Meng, F., Zhang, S., Oh, Y., Zhou, Z., Shin, H.-S. and Chae, S.-R.

579 (2017) Fouling in membrane bioreactors: An updated review. Water 580 Research 114(Supplement C), 151-180.

581 Menniti, Adrienne, Morgenroth and Eberhard (2010) The influence 582 of aeration intensity on predation and EPS production in membrane 583 bioreactors. Water Research 44(8), 2541-2553.

584 Menniti, A., Kang, S., Elimelech, M. and Morgenroth, E. (2009)

585 Influence of shear on the production of extracellular polymeric 586 substances in membrane bioreactors. Water Research 43(17), 43055874315. 
588 Mezger, T.G. (2011) The rheology handbook : for users of rotational

589 and oscillatory rheometers, Vincentz Network, Hanover, Germany.

590 Pollice, A., Giordano, C., Laera, G., Saturno, D. and Mininni, G. (2007)

591 Physical characteristics of the sludge in a complete retention

592 membrane bioreactor. Water Research 41(8), 1832-1840.

593 Schonhorn, H. (1965) Theoretical relationship between surface

594 tension and cohesive energy density. The Journal of Chemical

595 Physics 43(6), 2041-2043.

596 Sheng, G.-P., Yu, H.-Q. and Li, X.-Y. (2010) Extracellular polymeric

597 substances (EPS) of microbial aggregates in biological wastewater

598 treatment systems: A review. Biotechnology Advances 28(6), 882-

599894.

600 Sikorski, D., Tabuteau, H. and de Bruyn, J.R. (2009) Motion and

601 shape of bubbles rising through a yield-stress fluid. Journal of Non-

602 Newtonian Fluid Mechanics 159(1-3), 10-16.

603 Su, B., Qu, Z., Song, Y., Jia, L. and Zhu, J. (2014) Investigation of

604 measurement methods and characterization of zeta potential for

605 aerobic granular sludge. Journal of Environmental Chemical

606 Engineering 2(2), 1142-1147.

607 Sutherland, I.W. (2001) Exopolysaccharides in biofilms, flocs and

608 related structures. Water Science and Technology 43(6), 77.

609 Trussell, R.S., Merlo, R.P., Hermanowicz, S.W. and Jenkins, D. (2007)

610 Influence of mixed liquor properties and aeration intensity on

611 membrane fouling in a submerged membrane bioreactor at high

612 mixed liquor suspended solids concentrations. Water Research

613 41(5), 947-958.

614 Vold, M.J. (1982) Zeta potential in colloid science. Principles and

615 applications. Journal of Colloid and Interface Science 88(2), 608.

616 Wilén, B.-M., Jin, B. and Lant, P. (2003) The influence of key

617 chemical constituents in activated sludge on surface and flocculating

618 properties. Water Research 37(9), 2127-2139.

619 Yuan, H., Zhu, N. and Song, F. (2011) Dewaterability characteristics

620 of sludge conditioned with surfactants pretreatment by electrolysis.

621 Bioresource Technology 102(3), 2308-2315.

622 Zhang, Y., Zhang, P., Guo, J., Ma, W., Fang, W., Ma, B. and Xu, X.

623 (2013) Sewage sludge solubilization by high-pressure

624 homogenization. Water Science and Technology 67(11), 2399.

625 Zhang, Z., Zhu, J. and Park, K.J. (2004) Effects of Duration and

626 Intensity of Aeration on Solids Decomposition in Pig Slurry for Odour

627 Control. Biosystems Engineering 89(4), 445-456. 


\section{ACCEPTED MANUSCRIPT}

Table 1: Change of sludge elastic modulus ( $\left.G^{\prime}\right)$ at four different $(3 \%, 4 \%, 5 \%$, and $5.5 \%)$ total solids concentration of waste activated sludge and at four different gas injection intensities (percentage of change in elastic modulus was calculated in comparison to non-aerated sludge at the similar solid concentrations)

\begin{tabular}{|c|c|c|c|c|}
\hline \multirow{2}{*}{$\begin{array}{c}\text { Total solids } \\
\text { concentration (\%) }\end{array}$} & \multicolumn{4}{|c|}{ Percentage change in sludge elastic modulus (\%) } \\
\hline & 1LPM & 3LPM & 5LPM & 7LPM \\
\hline $3 \%$ & $18 \%$ & $25 \%$ & $30 \%$ & $37 \%$ \\
\hline $4 \%$ & $13 \%$ & $21 \%$ & $27 \%$ & $30 \%$ \\
\hline $5 \%$ & $5 \%$ & $11 \%$ & $20 \%$ & $26 \%$ \\
\hline $5.5 \%$ & $2 \%$ & $5 \%$ & $7 \%$ & $14 \%$ \\
\hline
\end{tabular}




\section{ACCEPTED MANUSCRIPT}

Table 2: Strain and stress imposed by four different gas velocities (1.82E-03 to 1.27E-02) at four different total solid concentrations of waste activated sludge (3\%, $4 \%, 5 \%$ and $5.5 \%)$

\begin{tabular}{|c|c|c|c|c|}
\hline $\begin{array}{l}\text { Total Concentration } \\
\text { (TS), } \\
\text { (g/g) }\end{array}$ & $\begin{array}{l}\text { Gas flow rate, } \\
\text { (L/min) }\end{array}$ & $\begin{array}{l}\text { Gas velocity, } \\
(\mathrm{m} / \mathrm{s})\end{array}$ & $\begin{array}{l}\text { Strain } \\
\text { imposed } \\
\text { (\%) }\end{array}$ & $\begin{array}{l}\text { Stress imposed } \\
\text { calculated from Eq.1 } \\
\left(\mathrm{N} / \mathrm{m}^{2}\right)\end{array}$ \\
\hline \multirow[t]{4}{*}{0.03} & 1 & $1.82 \mathrm{E}-03$ & $4.00 \mathrm{E}-02$ & 4.4564 \\
\hline & 3 & $5.46 \mathrm{E}-03$ & $7.00 \mathrm{E}-02$ & 7.7987 \\
\hline & 5 & $9.10 \mathrm{E}-03$ & $9.00 \mathrm{E}-02$ & 10.0269 \\
\hline & 7 & $1.27 \mathrm{E}-02$ & $1.30 \mathrm{E}-01$ & 14.4833 \\
\hline \multirow[t]{4}{*}{0.04} & 1 & $1.82 \mathrm{E}-03$ & $1.50 \mathrm{E}-02$ & 2.67855 \\
\hline & 3 & $5.46 \mathrm{E}-03$ & $3.00 \mathrm{E}-02$ & 5.3571 \\
\hline & 5 & $9.10 \mathrm{E}-03$ & $4.00 \mathrm{E}-02$ & 7.1428 \\
\hline & 7 & $1.27 \mathrm{E}-02$ & $6.00 \mathrm{E}-02$ & 10.7142 \\
\hline \multirow[t]{4}{*}{0.05} & 1 & $1.82 \mathrm{E}-03$ & $5.00 \mathrm{E}-03$ & 2.42791 \\
\hline & 3 & $5.46 \mathrm{E}-03$ & $8.00 \mathrm{E}-03$ & 3.884656 \\
\hline & 5 & $9.10 \mathrm{E}-03$ & $1.00 \mathrm{E}-02$ & 4.85582 \\
\hline & 7 & $1.27 \mathrm{E}-02$ & $2.00 \mathrm{E}-02$ & 9.71164 \\
\hline \multirow[t]{4}{*}{0.055} & 1 & $1.82 \mathrm{E}-03$ & $2.00 \mathrm{E}-03$ & 1.04614 \\
\hline & 3 & $5.46 \mathrm{E}-03$ & $6.00 \mathrm{E}-03$ & 3.13842 \\
\hline & 5 & $9.10 \mathrm{E}-03$ & $8.00 \mathrm{E}-03$ & 4.18456 \\
\hline & 7 & $1.27 \mathrm{E}-02$ & 0.01 & 5.2307 \\
\hline
\end{tabular}




\section{ACCEPTED MANUSCRIPT}

Table 3: Impact of gas velocity on soluble COD (sCOD) at four different total solid concentrations (3\%, $4 \%, 5 \%, 85.5 \%)$ of waste activated sludge.

\begin{tabular}{|c|c|c|c|c|}
\hline \multirow{2}{*}{ Gas velocity (m/s) } & \multicolumn{4}{|c|}{ sCOD (mg/l) } \\
\cline { 2 - 5 } & 3\%Ts & 4\%TS & $\mathbf{5 \%}$ TS & $\mathbf{5 . 5 \% T S}$ \\
\hline 0 & 3720 & 3960 & 4740 & 5090 \\
\hline 0.00182 & 4060 & 4260 & 5390 & 5580 \\
\hline 0.00546 & 4960 & 5050 & 6000 & 6260 \\
\hline 0.0091 & 5340 & 5500 & 6520 & 6740 \\
\hline 0.01274 & 6340 & 6680 & 7120 & 7290 \\
\hline
\end{tabular}




\section{ACCEPTED MANUSCRIPT}

Table 4: Impact of gas velocity on Surface tension at four different total solid concentrations $(3 \%, 4 \%, 5 \%, \& 5.5 \%)$ of waste activated sludge.

\begin{tabular}{|l|l|l|l|l|}
\hline \multirow{2}{*}{ Gas Velocity } & \multicolumn{4}{|c|}{ Surface Tension (mN/m) } \\
\cline { 2 - 6 } & $3 \%$ & $4 \%$ & $5 \%$ & $5.5 \%$ \\
\hline 0 & & & & \\
\hline 0.00182 & 46.04 & 46.4 & 59.45 & 60.04 \\
\hline 0.00546 & & & & 65.9 \\
\hline 0.0091 & 49.5 & 48.91 & 65.68 & 67.9 \\
\hline 0.01274 & 52.68 & 54.43 & 67.72 & 70.45 \\
\hline & 54.1 & & & 73.9 \\
\hline
\end{tabular}




\section{List of Figure}

\begin{tabular}{|l|l|}
\hline \multicolumn{1}{|c|}{ Figure No } & \multicolumn{1}{|c|}{ Caption of Figure } \\
\hline Figure 1 & $\begin{array}{l}\text { Impact of gas injection on 3\% total solids concentration of WAS at four } \\
\text { different gas flow rate (1-7LPM) measured through Time sweep test }\end{array}$ \\
\hline Figure 2 & $\begin{array}{l}\text { Stress imposed at different gas velocity for four different concentrations of } \\
\text { waste activated sludge (3\%, 4\%, 5\% \& 5.5\% TS) }\end{array}$ \\
\hline Figure 3 & $\begin{array}{l}\text { Impact of gas velocity on suspended solids of waste activated sludge at four } \\
\text { different total solid concentrations (3\%, 4\%, 5\% \&5.5\%) }\end{array}$ \\
\hline Figure 4 & $\begin{array}{l}\text { Comparison of storage and loss modulus of 4\% waste activated sludge } \\
\text { immediately after 20 mins of gas injection at 3 LPM and after the resting time } \\
\text { for 40 mins. }\end{array}$ \\
\hline Figure 5 & $\begin{array}{l}\text { Impact of gas Velocity on Zeta Potential of waste activated sludge at four } \\
\text { different total solid concentrations (3\%, 4\%, 5\% \&5.5\%) }\end{array}$ \\
\hline Figure 6 & $\begin{array}{l}\text { Impact of gas velocity on percentage change in surface tension of waste } \\
\text { activated sludge at four different total solid concentrations (3\%, 4\%, 5\% } \\
\text { \&5.5\%) }\end{array}$ \\
\hline
\end{tabular}




\section{List of Table}

\begin{tabular}{|l|l|}
\hline \multicolumn{1}{|c|}{ Table No. } & \multicolumn{1}{|c|}{ Caption of Table } \\
\hline Table 1 & $\begin{array}{l}\text { Change of sludge elastic modulus (G') at four different (3\%, 4\%, 5\%, and 5.5\%) } \\
\text { total solids concentration of waste activated sludge and at four different gas } \\
\text { injection intensities (percentage of change in elastic modulus was calculated in } \\
\text { comparison to non-aerated sludge at the similar solid concentrations) }\end{array}$ \\
\hline Table 2 & $\begin{array}{l}\text { Strain and stress imposed by four different gas velocities (1.82E-03 to 1.27E-02) at } \\
\text { four different total solid concentrations of waste activated sludge (3\%, 4\%, 5\% and } \\
5.5 \%)\end{array}$ \\
\hline Table 3 & $\begin{array}{l}\text { Impact of gas velocity on soluble COD (sCOD) at four different total solid } \\
\text { concentrations (3\%, 4\%, 5\%, \& 5.5\%) of waste activated sludge. }\end{array}$ \\
\hline Table 4 & $\begin{array}{l}\text { Impact of gas velocity on Surface tension at four different total solid } \\
\text { concentrations (3\%, 4\%, 5\%, \& 5.5\%) of waste activated sludge. }\end{array}$ \\
\hline
\end{tabular}




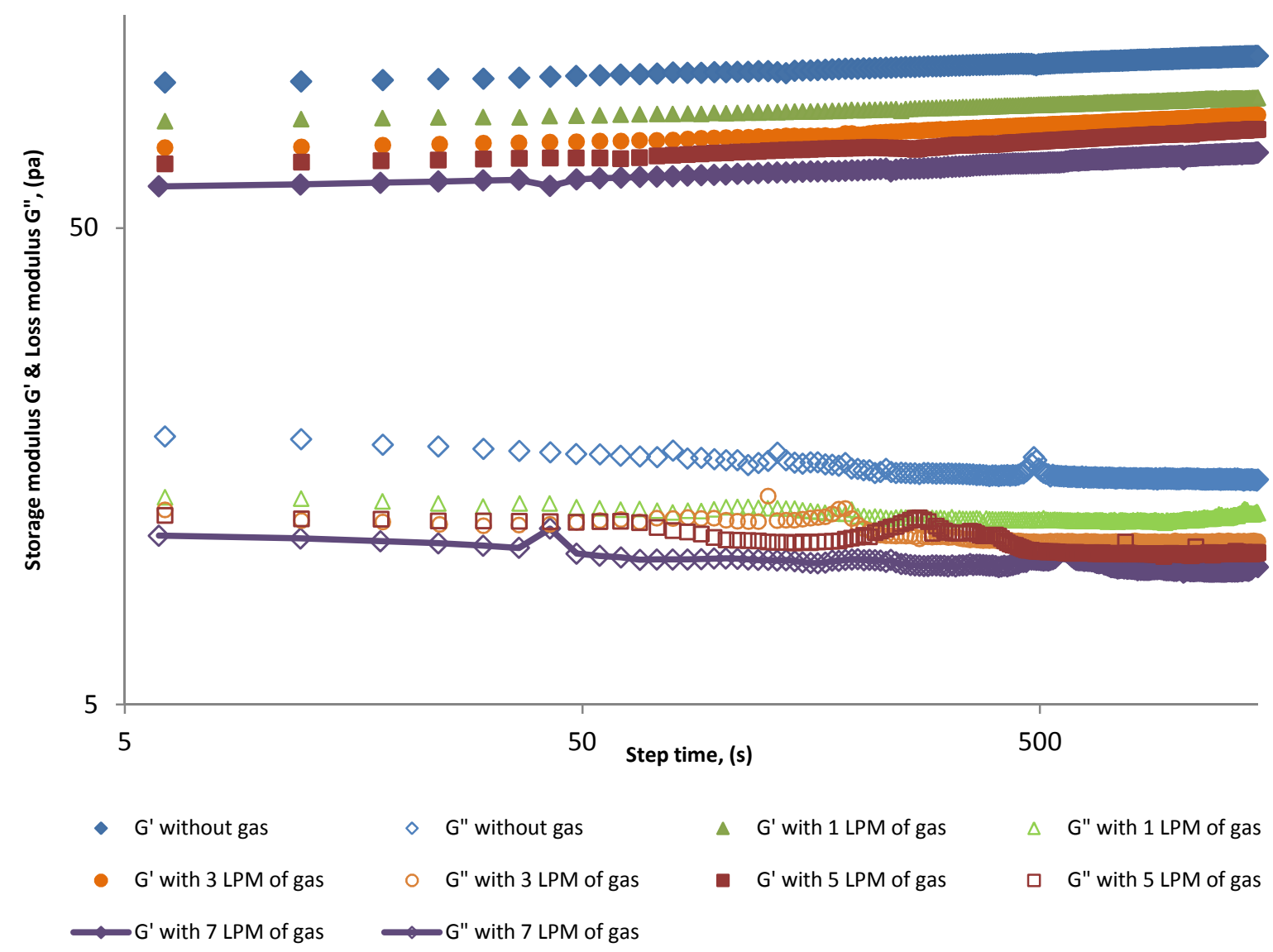

Figure 1: Impact of gas injection on $3 \%$ total solids concentration of WAS at four different gas flow rate (1-7LPM) measured through Time sweep test 


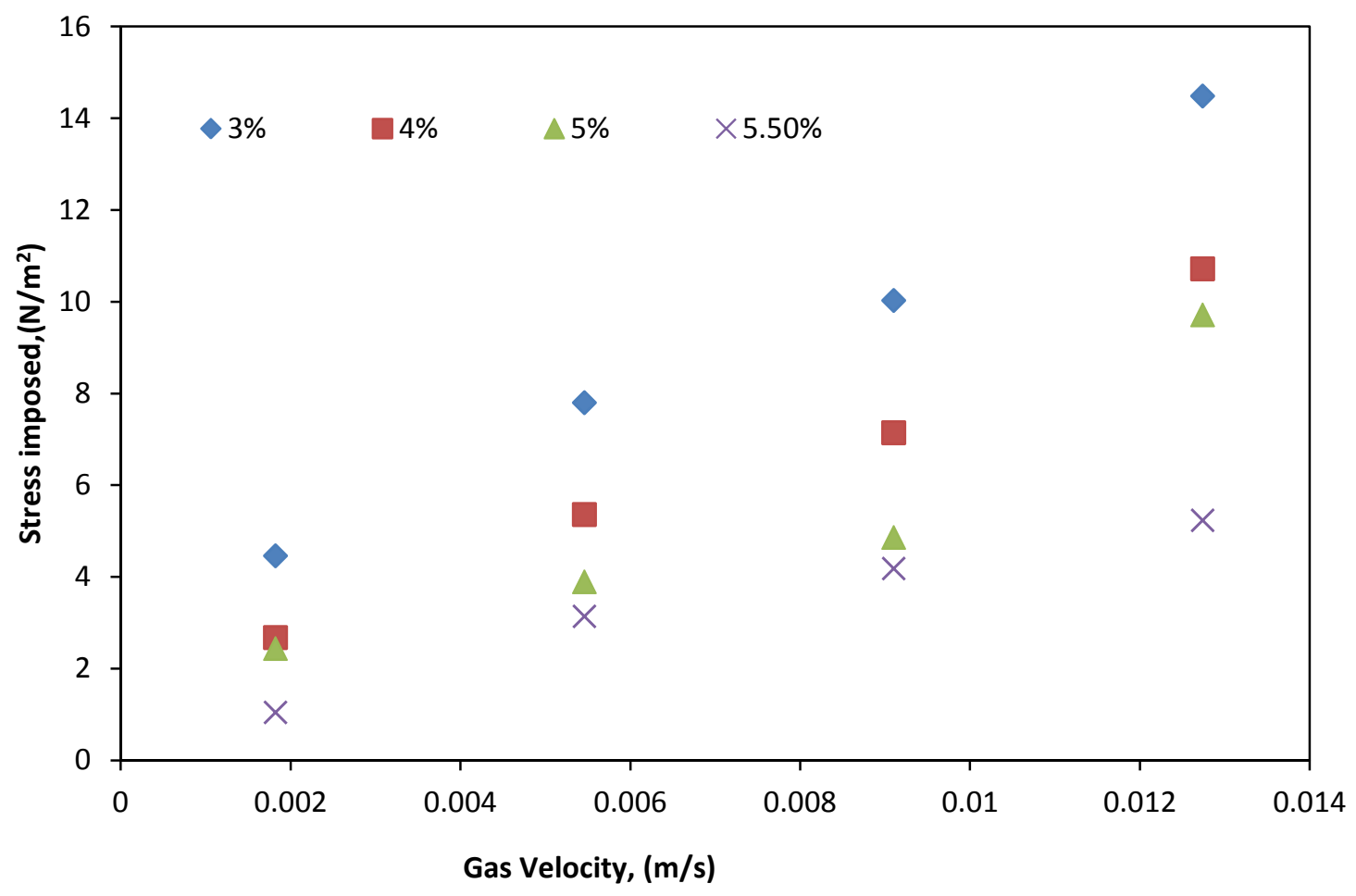

Figure 2: Stress imposed at different gas velocity for four different concentrations of waste activated sludge $(3 \%, 4 \%, 5 \%$ \& $5.5 \%$ TS) 


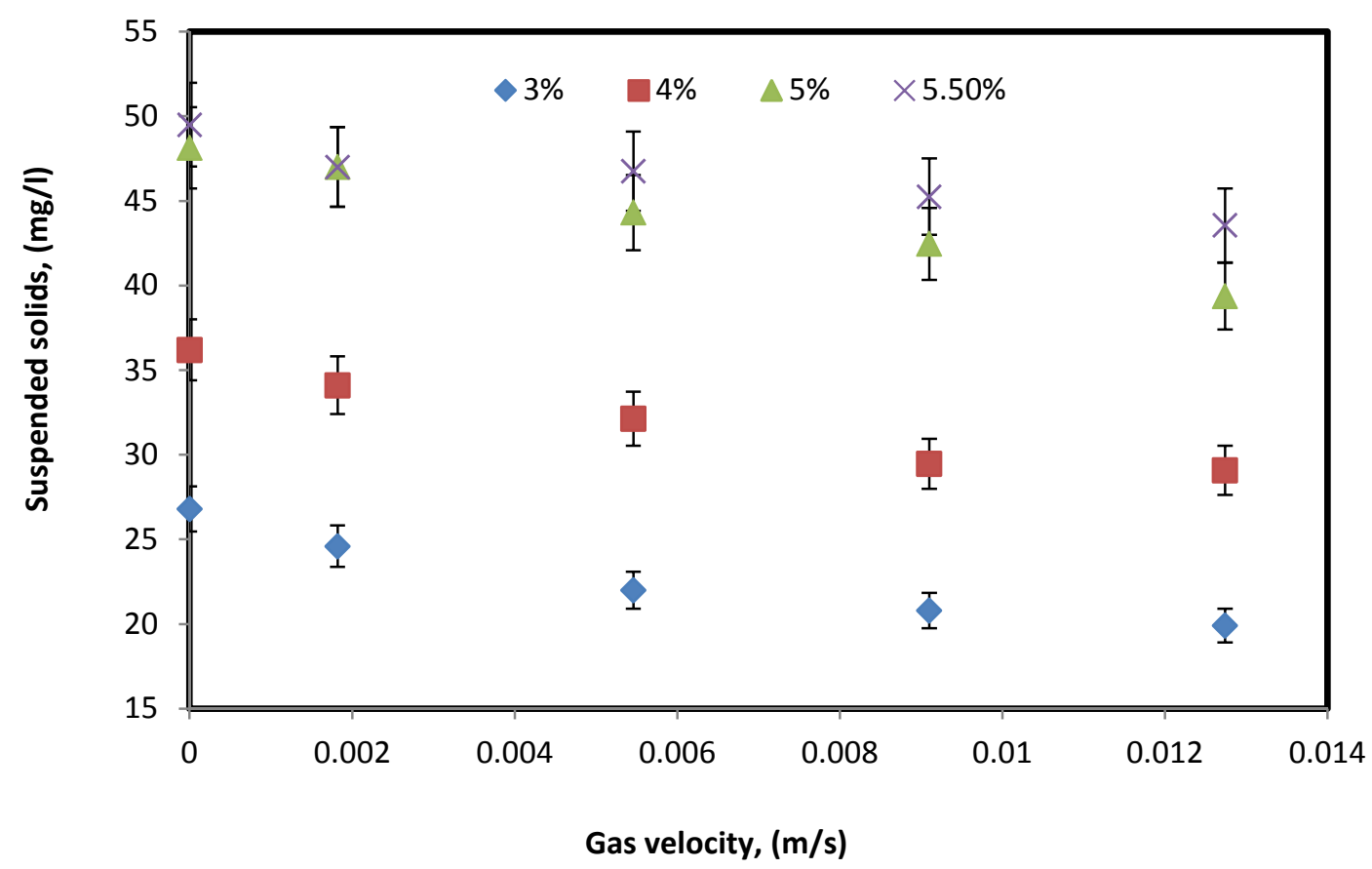

Figure 3: Impact of gas velocity on suspended solids of waste activated sludge at four different total solid concentrations $(3 \%, 4 \%, 5 \%$ \&5.5\%) 


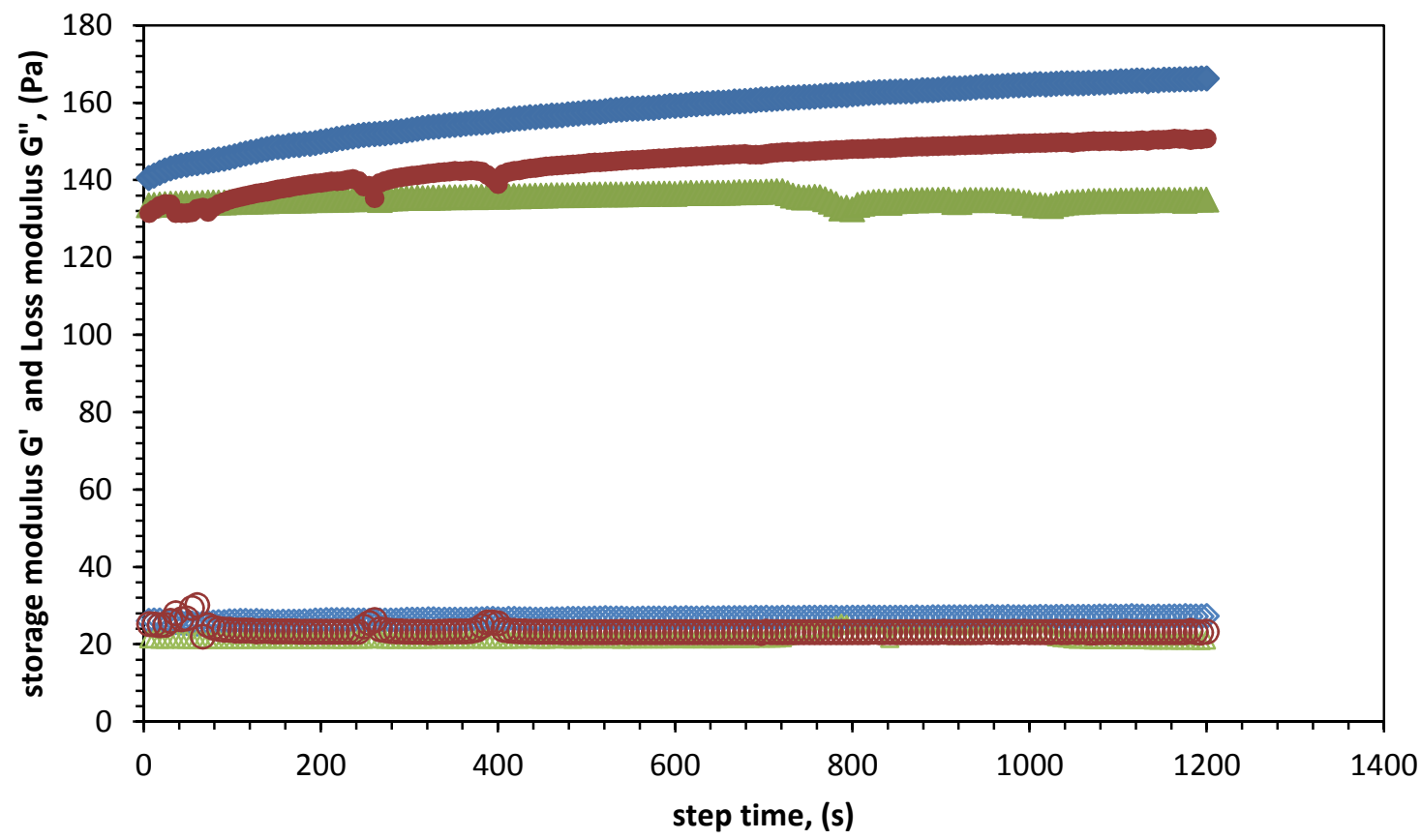

$\checkmark \mathrm{G}^{\prime} 4 \%$ ss without gas

$\diamond \mathrm{G} " 4 \%$ without gas

$\triangle \mathrm{G}^{\prime} 4 \%$ ss with 3 LPM

$\triangle G^{\prime \prime}$ with 3 LPM of gas

- G' $4 \%$ with 3 LPM of gas 40 mins wait

OG" $4 \%$ with 3 LPM of gas 40 mins wait

Figure 4: Comparison of storage and loss modulus of $4 \%$ waste activated sludge immediately after 20 mins of gas injection at $\mathbf{3}$ LPM and after the resting time for $\mathbf{4 0}$ mins. 
Gas Velocity, (m/s)

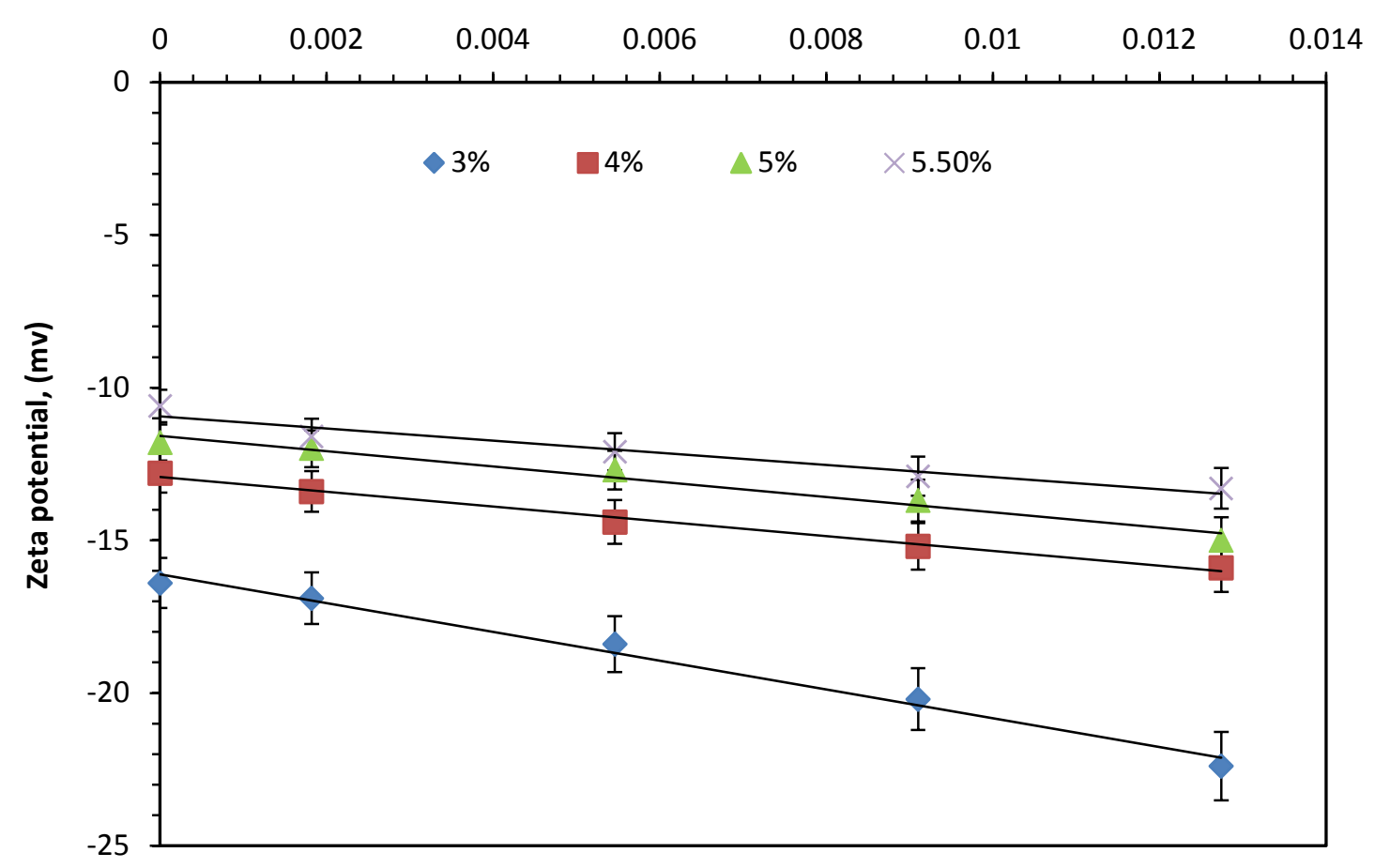

Figure 5: Impact of gas Velocity on Zeta Potential of waste activated sludge at four different total solid concentrations (3\%, 4\%, 5\% \&5.5\%) 


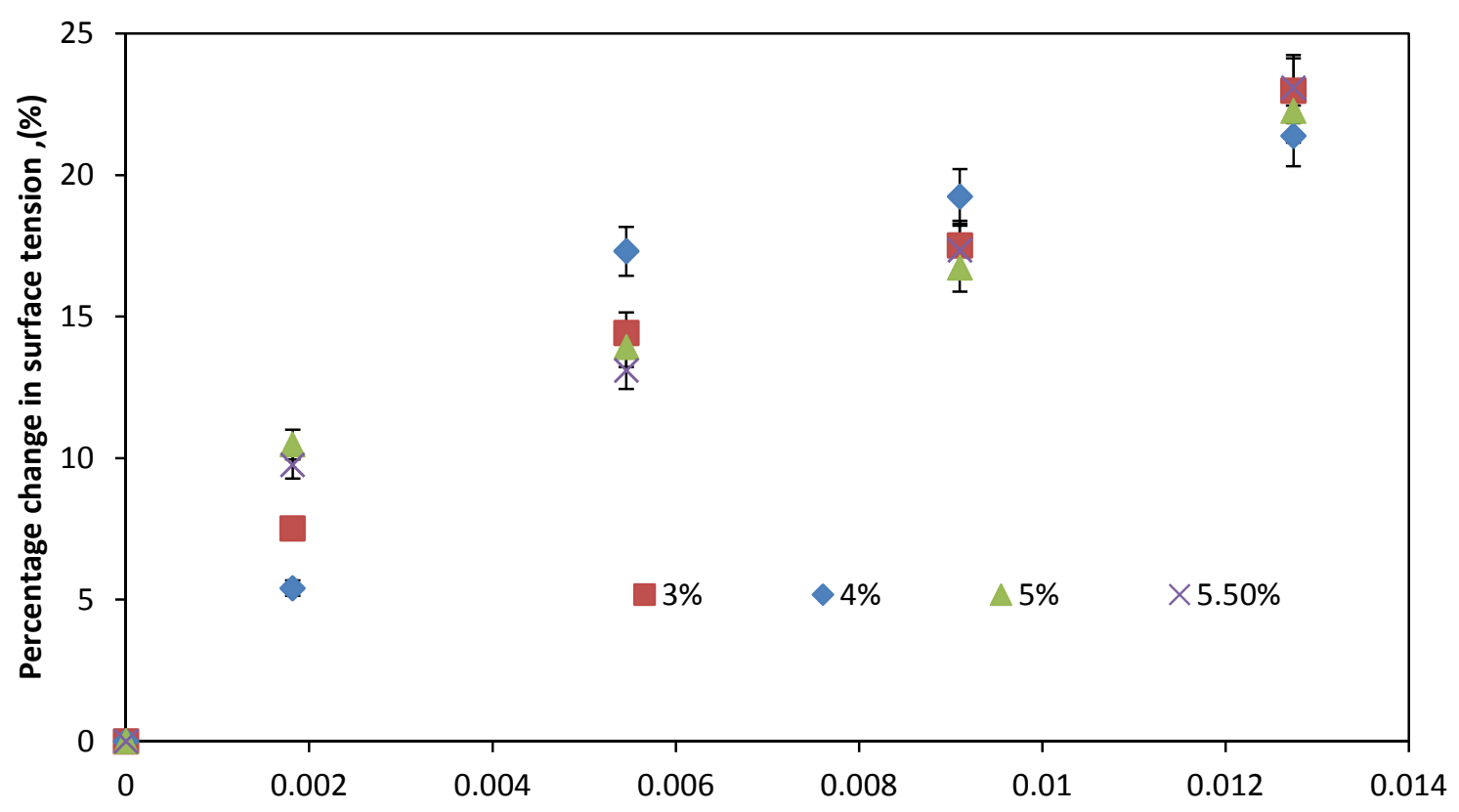

Gas velocity, $(\mathrm{m} / \mathrm{s})$

Figure 6: Impact of gas velocity on percentage change in surface tension of waste activated sludge at four different total solid concentrations $(3 \%, 4 \%, 5 \%$ \&5.5\%) 


\section{Highlights of the paper}

- Gas injection induces extra shear on sludge and changes its physicochemical properties.

- Developed a model to predict stress induced by gas injection.

- The change of physicochemical properties is proportional to stress imposed by gas injection. 